\title{
OS LAZERES DOS UNIVERSITÁRIOS DOS CURSOS DE PÓS-GRADUAÇÃO DE FORTALEZA - CE
}

Recebido em: 18/06/2013

Aceito em: 19/10/2014

\author{
Sílvia Fernandes do Vale ${ }^{1}$ \\ Regina Heloisa Mattei de Oliveira Maciel $^{2}$ \\ José Clerton de Oliveira Martins ${ }^{3}$ \\ Luiza de Andrade Braga Farias ${ }^{4}$ \\ Universidade de Fortaleza - UNIFOR \\ Fortaleza - CE - Brasil
}

RESUMO: Este estudo teve como objetivo investigar como os universitários, de cursos pós-graduação de Fortaleza-CE vivenciam suas atividades de lazer diante de suas demandas cotidianas. A amostra foi composta por 114 pós-graduandos, de ambos os sexos com idade entre 22 a 63 anos. Aplicou-se o questionário sociodemográfico, a Escala das Atividades de Hábitos de Lazer (EHL) acompanhada de uma questão alvo enfocando as principais atividades desenvolvidas no cotidiano. Os resultados revelaram que a média de atividades de lazer entre o publico investigado foi baixa $(\mathrm{M}=1,70 ; \mathrm{DP}=$ $0,77)$. Verificou-se significância estatística quanto ao gênero $(\mathrm{F}=6,359 ; \mathrm{gl}=1 ; \mathrm{p}<0,01)$ e a EHL, destacando-se o gênero feminino. As atividades de lazer que apresentaram maior média foram navegar na internet $(\mathrm{M}=3,37 ; \mathrm{DP}=1,54)$ e ler livros $(\mathrm{M}=2,84$; $\mathrm{DP}=$ 1,76). Os sujeitos elencaram o estudo e o trabalho como as atividades que desenvolvem na maior parte do seu tempo.

PALAVRAS CHAVE: Atividades de lazer. Trabalho. Pesquisa.

\section{LEISURE ACTIVITIES OF POST-GRADUATE STUDENTS OF FORTALEZA - CE}

ABSTRACT: This study aimed to investigation of leisure activities of post-graduate students of a university of Fortaleza-CE, given their everyday demands. The sample consisted of 114 students, of both sexes, aged 22 and 63 years. A socio-demographic questionnaire and the Scale of Leisure Habits (EHL) were applied. Besides that, a special question was added, asking about the normal activities performed in daily life. The results revealed that the average in the EHL was low $(\mathrm{M}=1.70 ; \mathrm{DP}=0.77)$ for the

1 Doutoranda em Psicologia pelo Programa de Pós-Graduação em Psicologia (PPGP/UNIFOR), pesquisadora do Laboratório de Estudos Sobre o Trabalho - LET (UNIFOR).

${ }^{2}$ Prof. Doutor do Programa de Pós-Graduação em Psicologia (PPGP/UNIFOR) e Coordenadora do Laboratório de Estudos Sobre o Trabalho - LET (UNIFOR).

3 Prof. Doutor do Programa de Pós-Graduação em Psicologia (PPGP/UNIFOR) e Coordenadora do Laboratório de Estudos Multidisciplinares sobre Ócio e Tempo Livre - OTIUM (UNIFOR).

4 Doutoranda em Psicologia pelo Programa de Pós-Graduação em Psicologia (PPGP/UNIFOR), pesquisadora do Laboratório de Estudos Sobre o Trabalho - LET (UNIFOR). 
group investigated. Gender differences were statistically significant $(\mathrm{F}=6.359, \mathrm{df}=1$; $p<0.01)$ regarding leisure activities, favouring women. Leisure activities that showed high average were surf the internet $(\mathrm{M}=3.37, \mathrm{DP}=1.54)$ and reading books $(\mathrm{M}=2.84$; $\mathrm{DP}=1.76)$. The students reported study and work as being the activities that they do during the most part of your time.

KEYWORDS: Leisure activities. Work. Research.

\section{INTRODUÇÃO}

Tempo. Essa simples palavra que cada vez mais significa algo escasso, que está se esvaindo e não se tem mais. No dia a dia podem-se ver, cada vez mais, as pessoas reclamando da falta do tempo e de como o dia deveria ter 48 horas. O ritmo de trabalho aumenta para que se possa ter mais tempo, que seria livre, mas o tempo livre é realmente livre? Ou o que na verdade se faz é aumentar o tempo para que se tenha mais espaço para nossas obrigações? Tem-se tempo para o lazer? Com as diversas demandas da sociedade moderna é possível ter um tempo para o lazer? E como seria esse lazer?

O tempo de lazer não está vinculado com normas ou regras da sociedade e sim com uma escolha relacionada à satisfação de necessidades reais do indivíduo. Há uma desvinculação entre o desejo de lazer do indivíduo e o que a sociedade lhe solicita. Porém, o lazer e sua definição foram constituídos historicamente, sempre dialogando com a sociedade e com suas normas, dessa forma, ele não pode ser pensado apenas como uma vontade individual, mas uma vontade inserida num contexto social (RODRIGUES; STEVAUX, 2010).

Silva (2008) afirma que o lazer é uma prática social que se constitui enquanto “dimensão da cultura, capaz de promover a conscientização dos indivíduos através de suas experiências lúdicas e não lúdicas, de diversos conteúdos culturais em um tempo e espaço próprios, tendo como dimensão fundamental a intencionalidade do ser" (SILVA, 
2008, p. 20-21). Essa definição amplia o conceito de lazer, como uma atividade que se constitui dentro de um contexto, não sendo uma simples escolha individual.

Um hábito de lazer geralmente está relacionado ao cotidiano das pessoas, as relações desenvolvidas com os pares, a partir das orientações que recebem, sendo capazes de influenciar psicossocialmente as condutas dos jovens, especialmente as que são referentes ao lazer; esses hábitos contribuem para que o jovem busque o equilíbrio entre o fazer e o pensar na prática do repouso e suas relações sociais (FORMIGA; AYROZA; DIAS, 2005; FORMIGA; DIAS, 2002). O lazer é considerado um elemento importante da vida das pessoas, no entanto, ainda limita-se a algumas atividades praticadas nos finais de semana (QUEIROZ; SOUZA, 2009).

Formiga, Ayroza e Dias (2005) na tentativa de elaborar um modelo das atividades relacionadas a hábitos de lazer em jovens brasileiros, distribuíram as atividades de diversão relatadas pelos jovens fora das suas obrigações diárias em três dimensões: hábitos de lazer hedonistas, lúdicos e instrutivos. O lazer hedonista assume característica de consumo, com ênfase no prazer individual e imediato com aspectos egoístas e individualistas; já o lúdico se relaciona exclusivamente à diversão, como jogar, passear e divertimentos em geral, lazer esse que pode ser experimentado sozinho ou em grupo; enquanto a dimensão instrutiva tem seu foco na formação cultural, intelectual (experiências de aperfeiçoamento e crescimento do indivíduo).

Oliveira et al. (2013) tratou-se de identificar as formas de lazer usufruídas por graduandos e pós-graduandos, os autores observaram que a atividade de lazer "passear" se destacou na amostra estudada. Passear é uma atividade de lazer que pode ser experimentada sozinha ou em grupo, capaz de gerar uma socialização quando vivida com outras pessoas (FORMIGA; MELO; LIMA, 2013). 
Sennet (2010) discute que laços sociais frouxos, decorrentes da atual cultura do capitalismo, aumentam a probabilidade de correr riscos, seja no trabalho ou na vida pessoal, o que pode levar a desorientação e incerteza, a ambiguidades, já que se têm cada vez mais opções de escolhas, mas não se sabe o que realmente se quer e qual a verdadeira vontade. Vive-se uma liberdade imaginária onde as propagandas não vendem mais produtos, vendem desejos, e só se descobre os desejos pessoais depois que determinado produto é lançado no mercado. Há uma ausência de repouso interior que gera uma incapacidade de aproveitar o tempo sem obrigações. Não se consegue mais parar, trabalha-se excessivamente, não se consegue mais desligar os celulares, nem sair da internet, porque não se pode parar. Vivendo assim, como fica o lazer?

Dentro do contexto acadêmico não é diferente. A pressão para produzir artigos, realizar pesquisas, cursar as disciplinas e ao mesmo tempo ser criativo o suficiente para produzir uma dissertação ou tese influencia a forma como se lida com o tempo e a quantidade de tempo dedicado ao lazer. É raro encontrar no Brasil estudantes de pós graduação que se dedique apenas ao estudo e à pesquisa e que tenha uma bolsa como única fonte de renda. A maioria dos pesquisadores também tem outro trabalho como atividade para aumentar sua renda mensal e vive a angústia de lidar com as diversas demandas da contemporaneidade.

O trabalho na contemporaneidade, incluindo o trabalho dos professores e estudantes de pós graduação, em vez de revelar a humanidade, satisfazer as necessidades vitais básicas e exteriorizar a capacidade criadora e inovadora, surge como trabalho alienado, em que o trabalhador não se reconhece no produto final, não realiza nenhuma capacidade humana, apenas cumpre as exigências do modelo capitalista. É exatamente isso que vemos no mundo do trabalho contemporâneo. As pessoas 
literalmente dedicam-se a maior parte do seu tempo ao trabalho, comprometendo os finais de semana para conseguir renda extra para o consumo (SALIS, 2008).

Diante das angústias que diariamente envolvem o contexto dos pesquisadores e estudantes de pós graduação definiu-se como objetivo desta pesquisa investigar como os estudantes de pós-graduação stricto sensu de uma Universidade de Fortaleza vivenciam o seu tempo de lazer diante da demanda das várias atividades acadêmicas e profissionais. Pretende-se, dessa forma, conhecer como os estudantes lidam com o seu tempo de lazer e conhecer melhor quais são as formas de lazer utilizadas pelos pósgraduandos.

\section{MÉTODO}

\section{População e amostra}

A pesquisa foi desenvolvida numa instituição de ensino superior particular de Fortaleza-CE, no ano de 2013.

Compuseram a amostra 114 estudantes do curso de pós-graduação stricto sensu (mestrado e doutorado) dos cursos de psicologia, administração, saúde coletiva, informática e direito. A amostra foi, portanto, intencional, por conveniência, visto que o estudante era convidado a participar, respondendo o questionário.

A Tabela 1 apresenta a análise descritiva dos dados sociodemográficos. A amostra ficou composta por $83,3 \%(n=95)$ de mestrandos e 16,7\% $(n=19)$ de doutorandos, com maioria do sexo feminino $57 \%(n=65)$ e $43 \%(n=40)$ do sexo masculino. A média de idade dos respondentes foi de 34,58 anos $(\mathrm{DP}=8,63)$, variando de 22 anos a 63 anos de idade. 49,1\% (n= 56) são solteiros e 43,9\% (n=50) declararam- 
se casados. A maioria $66,7 \%(n=76)$ afirmou não ter filhos e $76,3 \%(n=87)$ possuía um parceiro fixo.

A renda mensal variou de zero a mais de 6 salários mínimos, com média de 3 a 6 salários mínimos. A maioria 47,4\% $(\mathrm{n}=54)$ dos estudantes declarou-se na classe econômica B.

A maioria $(83,3 \%)$ eram mestrandos. Quanto aos cursos de pós-graduação que frequentavam, destacaram os cursos de psicologia $(49,1 \%)$ e informática $(28,9 \%)$, dedicando mais de 20 horas semanais aos seus estudos $(\mathrm{M}=20,81$ horas; $\mathrm{DP}=12,94$ horas).

Quanto à profissão que os pós-graduandos declararam, duas delas se destacaram: $27,2 \%(n=31)$ eram psicólogos e 26,3\% $(n=30)$ professores, tendo uma carga horária de trabalho superior a 20 horas semanais $(\mathrm{M}=26,51$ horas; $\mathrm{DP}=18,05$ horas). No geral os entrevistados declararam dedicar 21 horas semanais $(\mathrm{DP}=13,0)$ aos seus estudos.

Tabela 1 - Características sociodemográficas dos estudantes de pós-graduação

\begin{tabular}{|c|c|c|}
\hline Características & $\mathbf{n}$ & $\%$ \\
\hline \multicolumn{3}{|c|}{ Sexo } \\
\hline Feminino & 65 & 57,0 \\
\hline Masculino & 49 & 43,0 \\
\hline Total & 114 & 100,0 \\
\hline \multicolumn{3}{|c|}{ Curso stricto sensu } \\
\hline Mestrando & 95 & 83,3 \\
\hline Doutorando & 19 & 16,7 \\
\hline Total & 114 & 100 \\
\hline \multicolumn{3}{|c|}{ Faixa etária (anos) } \\
\hline $22-32$ & 56 & 49,1 \\
\hline $33-43$ & 38 & 33,3 \\
\hline $44-54$ & 17 & 15,0 \\
\hline$\geq 55$ & 03 & 2,60 \\
\hline Total & 114 & 100,0 \\
\hline \multicolumn{3}{|c|}{ Estado civil } \\
\hline Solteiro & 56 & 49,1 \\
\hline Casado & 50 & 43,9 \\
\hline Separado & 8 & 7,0 \\
\hline Total & 114 & 100,0 \\
\hline
\end{tabular}




\begin{tabular}{|l|c|r|}
\hline \multicolumn{3}{|c|}{ Situação Conjugal } \\
\hline Com parceiro fixo & 87 & 76,3 \\
\hline Sem parceiro fixo & 27 & 23,7 \\
\hline Total & 114 & 100,0 \\
\hline \multicolumn{3}{|c|}{ Remuneração } \\
\hline Nenhuma & 13 & 11,4 \\
Até 3 salários & 18 & 15,8 \\
3 - 6 salários & 35 & 30,7 \\
> 6 salários & 48 & 42,1 \\
\hline Total & 114 & 100,0 \\
\hline \multicolumn{2}{|c|}{ Curso de Pós-Graduação } \\
\hline Psicologia & 56 & \\
Informática & 33 & 49,1 \\
Administração & 10 & 28,9 \\
Saúde Coletiva & 08 & 8,8 \\
Direito & 07 & 7,0 \\
\hline Total & 404 & 6,2 \\
\hline \multicolumn{2}{|c|}{} & \\
\hline Psicólogo & Profissão & 100,0 \\
Professor & 31 & \\
Analista de Sistema & 30 & 27,2 \\
Estudante & 13 & 26,3 \\
Servidor Público & 07 & 11,4 \\
Advogado & 04 & 6,1 \\
Enfermeiro & 03 & 3,5 \\
Auditor Fiscal & 03 & \\
Consultor & 02 & 2,6 \\
Perito Criminal & 02 & \\
Outros & 02 & 1,6 \\
\hline Total & 17 & 1,8 \\
\hline
\end{tabular}

\section{Instrumento}

Os questionários foram aplicados coletivamente, em sala de aula com a autorização do professor responsável. O tempo utilizado para esclarecimentos, assinatura do termo de consentimento e aplicação dos instrumentos foi de aproximadamente 20 minutos. Apesar de o questionário ser autoaplicável e conter as informações necessárias para serem respondidos, os pesquisadores circulavam na sala resolvendo as eventuais dúvidas e/ou esclarecendo algumas questões durante a aplicação dos instrumentos. 
O questionário era composto de três partes. Para conhecer os aspectos sociodemográficos como: sexo, idade, estado civil, classe social, etc., foi criado um instrumento específico para caracterização dos sujeitos. Para a coleta de dados relacionada aos comportamentos de lazer utilizou-se a Escala de atividades de hábitos de lazer (EHL). Finalmente foi colocada aos participantes uma questão alvo sobre suas atividades diárias: “A maior parte das horas do seu dia é dedicada a quais atividades?".

A Escala de atividades de hábitos de lazer (EHL), desenvolvida por Formiga, Ayroza e Dias (2005), consta de 23 questões que avaliam as atividades de lazer assumidas pelo sujeito quando estão descansando ou no final de semana e feriados. A essa escala, foi acrescentada mais uma questão: "Viajar em excursões, visitas turísticas, feiras, etc.", a fim de atender as características desse público pesquisado, sendo que a escala final continha 24 itens. As respostas são pontuadas em uma escala tipo Likert de cinco pontos, variando de " $0=$ Nunca" a " $5=$ Sempre", sendo que " 0 " revela uma atitude nunca desenvolvida no lazer dos respondentes e " 5 " uma atitude sempre desenvolvida nas horas dedicadas ao lazer.

Formiga, Ayroza e Dias (2005) na construção da escala, a partir de uma análise fatorial, dividiram a escala em três fatores: hedonista, lúdico e instrutivo. O fator "hedonista", com 11 itens, apresentou um Alpha de Cronbach $(\alpha)$ de 0,80, explicando $18 \%$ da variância da escala; o segundo fator "lúdico" (6 itens) apresentou $\alpha=0,64$, explicando 4,5\% da variância e o terceiro "instrutivo" (6 itens), $\alpha=0,63$, explicando 5,5\% da variância. O item acrescentado na escala ("Viajar em excursões, visitas turísticas, feiras, etc.”) foi considerado como pertencente ao fator instrutivo. Embora os fatores não possuam uma confiabilidade alta, a escala como um todo apresentou $\alpha=0,82$, 
explicando $27,9 \%$ da variância, valores considerados suficientes em termos de confiabilidade.

Os dados foram tabulados e processados utilizando-se o SPSS v. 20.0 (Statistical Package for the Social Sciences v. 20.0). Foram realizadas análises estatísticas descritivas de frequência e tendência central e dispersão. Para a comparação entre médias foi utilizada a ANOVA.

Este projeto foi submetido à avaliação do Comitê de Ética em Pesquisa da Universidade de Fortaleza-CE, sob o número de registro CEP No 133/2008 e foi aprovado no dia $02 / 06 / 2008$, tendo-se respeitados todos os preceitos éticos, garantidos aos sujeitos da pesquisa os direitos ao sigilo das informações e a privacidade.

\section{RESULTADOS}

A análise dos itens da Escala de atividades de hábitos de lazer - EHL foi realizada por meio das medidas de tendência central (média) e dispersão (desviopadrão). Os itens são apresentados na Tabela 2 em ordem decrescente da média das respostas do grupo pesquisado. Foi identificada uma hierarquia decrescente das atividades de lazer, tendo em primeiro lugar as atividades: "navegar na internet", "ler livros" e "encontrar-se com alguém". Ao final da tabela são apresentados o escore médio global e os escores nos três fatores. Nota-se que o maior escore médio se refere aos lazeres hedonistas, seguido dos lazeres instrutivos e, por último, dos lazeres relacionados aos fatores lúdicos.

Foi realizada uma análise de variância (ANOVA) para verificar a existência de diferença estatisticamente significativa nas atividades de lazer (três fatores da escala) com relação às variáveis: sexo, idade, estado civil, situação conjugal, tipo de pós- 
graduação (mestrado ou doutorado). Desses, apresentaram diferenças estatisticamente significativas apenas em relação ao sexo no que se refere ao escore global da escala $(\mathrm{F}=6,359 ; \mathrm{gl}=1 ; \mathrm{p}<0,05)$ e nos fatores hedonista e instrutivo. No fator hedonista as mulheres apresentaram uma média mais elevada (Mulheres=2,29; Homens $=1,82$; $\mathrm{F}=7,425 ; \mathrm{gl}=1 ; \mathrm{p}<0,05)$. Do mesmo modo, no fator instrutivo, os homens apresentam média mais baixa do que as mulheres (Mulheres=1,96; Homens=1,51; $\mathrm{F}=6,231$; $\mathrm{gl}=1$; $\mathrm{p}<0,05)$. No escore global, as mulheres também apresentam média mais alta (Mulheres=1,86; Homens=1,49).

Tabela 2 - Média e Desvio-Padrão das atividades de lazer de Mestrandos e Doutorandos

\begin{tabular}{|l|r|r|}
\hline Itens da Escala & Média & DP \\
\hline Navegar na internet (MSN, facebook, etc.) & 3,37 & 1,54 \\
\hline Ler livros & 2,84 & 1,76 \\
\hline Encontrar-se com alguém (amigos, paquera, etc.) & 2,68 & 1,51 \\
\hline Assistir a filmes em vídeo & 2,58 & 1,64 \\
\hline Ir a bares, boates, cafés ou restaurantes & 2,52 & 1,40 \\
\hline Assistir a programas de televisão & 2,45 & 1,65 \\
\hline Visitar familiares ou amigos & 2,44 & 1,53 \\
\hline Dirigir carro ou moto & 2,20 & 2,04 \\
\hline Jogar conversa fora, contar piadas, etc. & 2,17 & 1,70 \\
\hline Ler revistas & 2,01 & 1,61 \\
\hline Ler jornais & 1,96 & 1,66 \\
\hline Ir ao cinema & 1,84 & 1,44 \\
\hline Ir à igreja & 1,81 & 1,74 \\
\hline Comprar roupas & 1,69 & 1,29 \\
\hline Viajar em excursões, visitas turísticas, feiras, etc. & 1,66 & 1,48 \\
\hline Ir à praia & 1,45 & 1,39 \\
\hline Ir a shows, teatros, etc. & 1,34 & 1,23 \\
\hline Praticar esportes (basquete, futebol, etc) & 1,30 & 1,66 \\
\hline Fazer trabalhos manuais (pintar, escrever, fazer crochê, etc.) & 0,91 & 1,30 \\
\hline Ir à piscina & 0,86 & 1,14 \\
\hline Jogar videogames ou jogos de aventura e ação & 0,68 & 1,23 \\
\hline Jogar baralho, dominó, dados, bingo, etc. & 0,53 & 0,98 \\
\hline Visitar o jardim zoológico, reservas ecológicas, etc. & 0,50 & 0,98 \\
\hline Participar de passeatas em favor do fim dos problemas ambientais, \\
sociais e políticos & 0,39 & 0,88 \\
\hline Passear de bicicleta, patins, patinete, etc. & & \\
\hline Média Geral da Escala & 0,34 & 0,86 \\
\hline & $\mathbf{1 , 7 0}$ & $\mathbf{0 , 7 7}$ \\
\hline Hedonista & $\mathbf{2 , 0 9}$ & $\mathbf{0 , 9 4}$ \\
\hline Lúdico & $\mathbf{0 , 9 0}$ & $\mathbf{0 , 7 1}$ \\
\hline Instrutivo & $\mathbf{1 , 7 7}$ & $\mathbf{0 , 9 9}$ \\
\hline & & \\
\hline
\end{tabular}


Analisando-se os itens separadamente, verifica-se que as mulheres apresentaram uma média superior a dos homens em relação aos hábitos de lazer hedonista e instrutivo nas atividades: "comprar roupas" $(\mathrm{F}=19,547 ; \mathrm{gl}=1 ; \mathrm{p}<0,05)$, "jogar conversa fora, contar piadas, etc." $(\mathrm{F}=5,760 ; \mathrm{gl}=1 ; \mathrm{p}<0,05)$, "assistir programas de televisão" $(\mathrm{F}=$ $6,575 ; \mathrm{gl}=1 ; \mathrm{p}<0,05)$, "fazer trabalhos manuais (pintar, escrever, fazer crochê, etc.)" $(\mathrm{F}=4,038 ; \mathrm{gl}=1 ; \mathrm{p}<0,05)$, "visitar familiares ou amigos" $(\mathrm{F}=7,420, \mathrm{gl}=1 ; \mathrm{p}<0,05) \mathrm{e}$ "viajar em excursões, visitas turísticas, feiras, etc." $(F=6,328 ; \mathrm{gl}=1 ; \mathrm{p}<0,05)$. Esta situação se inverteu no caso do Lúdico, onde os homens pontuaram com média superior a das mulheres Figura 1 na atividade de lazer "jogar videogames ou jogos de aventura e ação" $(\mathrm{F}=4,381 ; \mathrm{gl}=1 ; \mathrm{p}<0,05)$.

Figura 1 - Comparação das médias nos itens da escala de lazer entre homens e mulheres (esses itens apresentaram diferenças estatisticamente significativas)

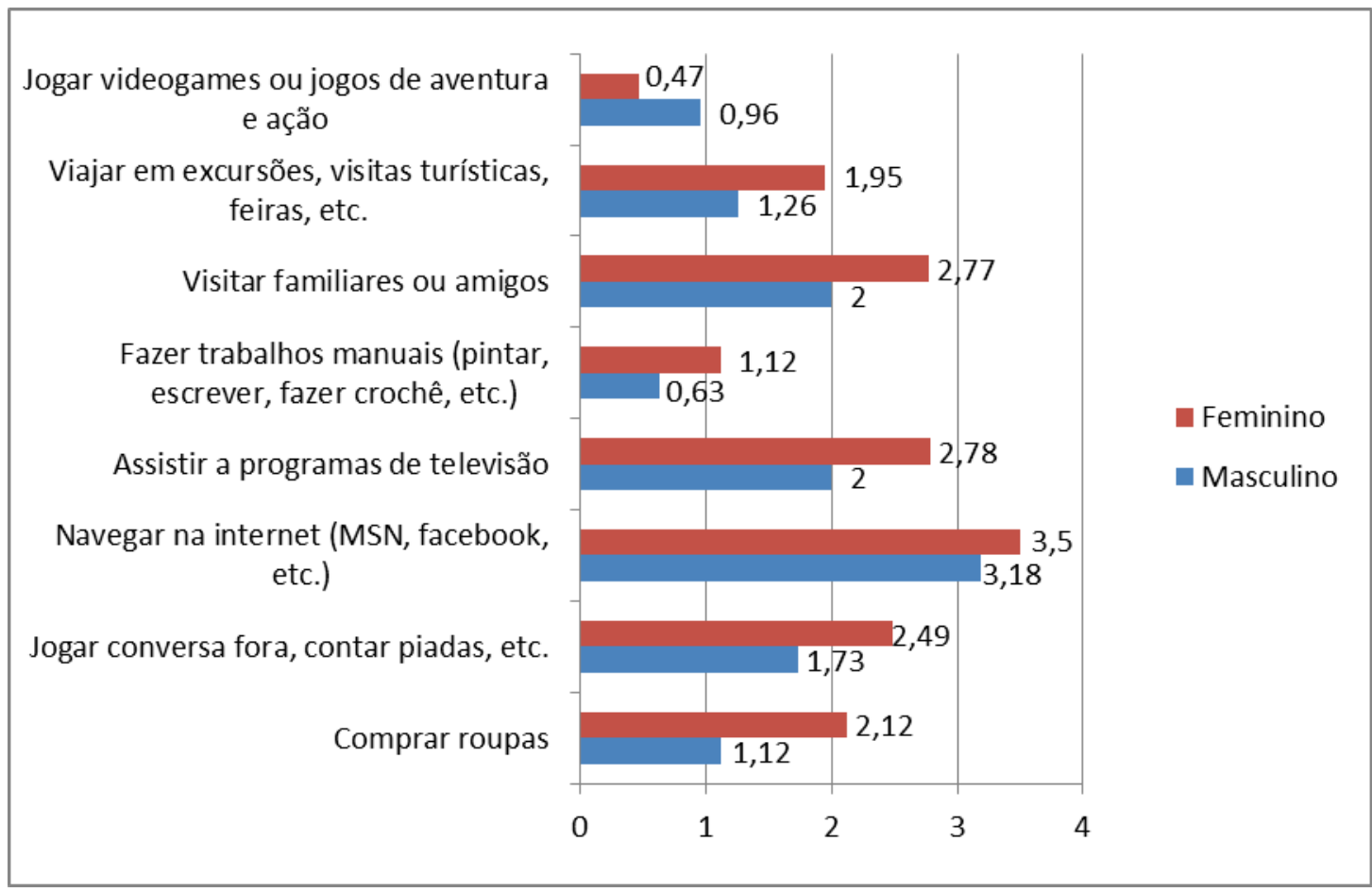


No questionário solicitava-se ainda ao respondente que ele apontasse as atividades que dedicava a maior parte das horas do seu dia. Foram citadas 243 atividades pelos 114 pós-graduandos (TABELA 3). De modo geral, as respostas analisadas possibilitaram observar uma grande variedade de atividades que estavam relacionadas ao trabalho e algumas passíveis de serem consideradas como lazer (geradora de momentos de prazer, tempo livre de obrigações).

As atividades relacionadas ao ato de estudar $(n=96 ; 39,5 \%)$, e trabalhar, $(\mathrm{n}=75 ; 30,9 \%)$ se destacaram entre os pós-graduandos como principais ocupações no seu dia a dia. As atividades que tiveram menor frequência foram classificadas como "outras". Essas atividades envolviam: vida social, assistir tv, sair com os amigos, praticar esporte, namorar, ministrar aula, lazer, igreja, esporte, escrever, dormir, dirigir e cinema.

Tabela 3 - Frequência de respostas das atividades realizadas na maior parte do dia

\begin{tabular}{|l|c|c|}
\hline \multicolumn{1}{|c|}{ Atividades } & F & \% \\
\hline Estudar & 96 & 39,5 \\
Trabalhar & 75 & 30,9 \\
Família & 23 & 9,5 \\
Ler & 10 & 4,1 \\
Pesquisar & 07 & 2,9 \\
Navegar na internet & 05 & 2,0 \\
Organização do lar & 04 & 1,7 \\
Atividade física & 03 & 1,2 \\
Outras & 20 & 8,2 \\
\hline Total & 243 & 100,0 \\
\hline
\end{tabular}

\section{DISCUSSÃO}

\section{Análise da amostra obtida}

Embora a amostra não seja uma amostra probabilística, sua análise fornece alguns indícios sobre a população estudada. Como já especificado, a amostra foi predominantemente de mestrandos. Esse dado pode ser justificado em virtude da 
Universidade exigir o título de mestre antes de entrar no programa de doutorado, além de, no Brasil, diferentemente dos Estados Unidos, o mestrado ser de natureza altamente acadêmica, como "porta de entrada" para o ensino universitário e para carreira de pesquisador (VERHINE, 2008).

Vale destacar, a forte participação das mulheres (57\%), especialmente no curso de doutorado, dado este em consonância com os dados fornecidos pelo Centro de Gestão e de Estudos Estratégicos (CGEE, 2010) onde afirmam que desde 2004 o número de mulheres em cursos de doutorado no Brasil passou a ser maioria em relação aos homens, visto que, em 1996 as mulheres representavam apenas 43\% da amostra dos doutores titulados no Brasil.

A maioria dos pós-graduandos entrevistados não possuíam filhos, apesar de declararem ter um parceiro fixo. Esses dados confirmam a pesquisa desenvolvida pelo Instituto Brasileiro de Geografia e Estatística - IBGE a qual mostra que, quanto maior a escolaridade, menor a taxa de fecundidade, o que pode explicar o pequeno número de mestrandos e doutorandos com filhos (IBGE, 2012). Um estudo desenvolvido em 66 diferentes universidades nos programas de mestrado e doutorado distribuídos pelas 5 regiões do Brasil, também mostrou que embora os pós-graduandos mantivessem relacionamentos estáveis, em geral não possuíam filhos (FARO, 2013).

\section{Escala de lazer}

A média geral de respostas para as atividades de lazer da amostra foi de 1,70 $(\mathrm{DP}=0,77)$. Considerando que as respostas podiam variar de 0 a 5 , em termos globais, os resultados se apresentaram consideravelmente críticos, visto que os estudantes 
demonstraram que destinam pouco tempo para atividades de lazer, com fins exclusivamente de distração ou entretenimento.

Vale destacar que os entrevistados declararam uma carga horária de trabalho superior a 20 horas semanais $(\mathrm{M}=26,51$ horas; $\mathrm{DP}=18,05$ horas $)$ e que dedicam, em média, 21 horas semanais $(\mathrm{DP}=13,0)$ aos seus estudos, justificando a falta de lazer, visto que, a maior parte do tempo dos pós-graduandos é dedicada ao trabalho e ao estudo.

Embora não tenham sido encontradas pesquisas com amostras similares e que, também, tenham utilizado o mesmo instrumento, pode-se inferir que o lazer ainda ocupa pouco tempo na rotina dos pós-graduandos, mesmo sendo considerado um elemento importante na vida das pessoas, limita-se a algumas atividades praticadas nos finais de semana (QUEIROZ; SOUZA, 2009), em virtude de acúmulos de atividades acadêmicas e de trabalho, geradoras de falta de tempo livre e lazer.

As práticas de lazer de maior destaque para os pós-graduandos são "Navegar na internet", seguida de "ler livros" e "encontrar-se com alguém (amigos, paquera, etc.)" (TABELA 2). A partir dos resultados, nota-se que os pós-graduandos preferem os hábitos de lazer hedonistas, as vivencias prazerosas, as satisfações geradas em momentos distantes das obrigações, atividades que estão relacionados ao consumo de algo que proporcione prazer individual e imediato como único bem possível do indivíduo, desenvolvido normalmente a partir das interações sociais como as das atividades citadas: navegar na internet e encontrar-se com alguém (paquera, amigos, etc.) (FORMIGA, MELO; LIMA, 2013).

Ressalta-se que, em virtude do aumento da disponibilidade das inovações tecnológicas numa sociedade globalizada como a nossa, a internet passa a ser 
considerada como atividade de lazer (SCHWARTZ, 2003), visto que o indivíduo procura a internet também para distrair-se, alcançar prazer, diversão e felicidade, aspectos característicos do lazer.

De acordo com Paim, et al. (2004), o uso da internet é uma ferramenta de grande importância e muito utilizada pelos acadêmicos como uma atividade intelectual praticada na sociedade globalizada, visto que é fonte de pesquisa e informação imediata, bem como, é utilizada para conversar com os colegas, que muitas vezes não tem tempo suficiente para encontrar-se presencialmente.

A terceira atividade de lazer mais praticada pelos pós-graduandos envolve relacionamento interpessoal, como encontrar-se com alguém (paquera, amigos, etc.). Esse dado corrobora os resultados encontrados na literatura onde as atividades de lazer associadas a relacionamentos interpessoais se destacam, em especial, com amigos e familiares (PRATTA; SANTOS, 2007; ZONTA; ROBLES; GROSSEMAN, 2006).

Os pós-graduandos da amostra estudada também têm um foco no lazer instrutivo, como "ler livros", segunda atividade de lazer de maior frequência, fato que pode ser justificado pelo nível cultural e de escolaridade da amostra. Em certa medida, os entrevistados demonstram preferência por atividades de lazer que proporcionam o aperfeiçoamento e crescimento, tornando-os capaz de escolhas de lazer diferenciados e exclusivos de cada pessoa (FORMIGA; AYROZA; DIAS, 2005). Formiga e Dias (2002) destacam que a investida nos hábitos de lazer instrutivo de jovens está diretamente relacionada com três fatores: a dedicação, o tempo de estudo e o autoconceito de um bom estudante, aspectos inerentes no dia a dia também dos pósgraduandos. 
Entre às atividades de lazer que receberam as médias mais baixas, destacam-se: "participar de passeatas em favor do fim dos problemas ambientais, sociais e políticos", "passear de bicicleta, patins, patinete, etc." e "visitar o jardim zoológico, reservas ecológicas, etc." (TABELA 2). Todas essas três atividades são caracterizadas como hábitos de lazer lúdico, atividades direcionadas à diversão, podendo ser experimentadas isoladamente ou em grupo. E, quando desenvolvidas em parceria podem gerar socialização (FORMIGA; MELO; LIMA, 2013).

Vale ressaltar, que não foram encontradas pesquisas com pós-graduandos que tenham utilizado a EHL para se desenvolver uma comparação entre os estudos. No entanto, os dados da pesquisa desenvolvida por Oliveira et al. (2013), que utilizaram como instrumento um questionário em pós-graduandos da Universidade Federal de Viçosa - MG apontaram "passear" como a atividade de lazer desenvolvida com mais frequência dentre as atividades de lazer prediletas dos pós-graduandos. Esses dados não estão de acordo com os encontrados aqui. Essa diferença pode ser explicada em termos das diferentes realidades das regiões brasileiras, levando em consideração a dinâmica cultural, de socialização, as condições socioeconômicas, entre outras. É possível que na cidade de Viçosa, dado o seu tamanho e condições de segurança, não haja impedimentos para passeios e existam espaços propícios para esse tipo de lazer. Ao contrário, a cidade de Fortaleza, capital do estado do Ceará, apresenta atualmente um dos maiores ( $7^{\circ}$ lugar) índices de violência do mundo (NASSIF, 2014) o que torna praticamente impossível, ou extremamente temeroso, praticar atividades ao ar livre nos parques e ruas.

No que se refere às diferenças de gênero encontradas, os resultados estão em consonância com estudos desenvolvidos por Formiga (2009); Formiga, Ayroza e Dias 
(2005), a qual as mulheres apresentam médias superiores a dos homens em relação aos fatores hedonista e instrutivo. Este resultado pode ser justificado pelas atribuições do gênero feminino em nossa sociedade. O gênero feminino, em geral, apresenta maior responsabilidade no que se refere aos seus estudos e passam grande parte de seu tempo em casa.

Com relação à pergunta sobre a dedicação de tempo (última pergunta do questionário), as atividades relacionadas ao ato de estudar $(n=96 ; 39,5 \%)$, e trabalhar, $(n=75 ; 30,9 \%)$ se destacaram entre os pós-graduandos como principais ocupações no seu dia a dia. Estes resultados podem estar relacionados ao fato de se tratar de uma população de estudantes-trabalhadores que necessitam dispor de tempo tanto para trabalhar quanto para estudar, restando-lhes menos tempo para descansar, se dedicar a atividades de lazer e mesmo para estudar fora da sala de aula.

Grande parte dos entrevistados deste estudo precisa trabalhar para custear seus estudos e, além da jornada de trabalho que necessitam cumprir, devem destinar uma parte do seu tempo para estudar. Isto pode explicar, em parte, porque os pós-graduandos dedicam-se pouco ao lazer. O mesmo resultado foi encontrado nas pesquisas de Oliveira, et al. (2013) e de Martoni e Schwarts (2006) onde se verificou que o trabalho e o estudo como fontes de impedimento à vivência de lazer. Isto pode ser um reflexo do estilo de vida capitalista que provoca inúmeras modificações na qualidade de vida da população. A velocidade na qual os acontecimentos surgem, a falta de tempo vivido pela população e o processo de industrialização impõe novo ritmo de vida que, consequentemente, entra em choque com as necessidades biológicas do homem, provocando desequilíbrio físico e psicológico. 
Mesmo em menor proporção, os pós-graduandos declararam dividir seu tempo com algumas atividades que, dependendo de como são planejadas e vivenciadas, podem ser consideradas como fontes de lazer, tais como família $(9,5 \%)$ e ler $(4,1 \%)$. Para Gutierrez e Almeida (2008) o objeto de lazer, é um conjunto de atividades individuais ou coletivas voltadas para a satisfação de uma série de interesses, desenvolvidas no tempo liberado das obrigações do trabalho e das responsabilidades sociais, voltadas para a satisfação, criação, formação e aprimoramento pessoal, entretenimento, etc. Uma prática capaz de promover a conscientização através de experiências lúdica e não lúdicas (SILVA, 2008).

\section{Considerações Finais}

O presente estudo apresentou dados coletados a partir especialmente da Escala de atividades de hábitos de lazer (EHL) em pós-graduandos de Fortaleza-CE. Procurouse não apenas contribuir para a literatura empírica do lazer, mas, sobretudo fornecer dados reais que possam conduzir para reflexões relacionadas aos aspectos conceituais e metodológicos implicados num estudo relacionado a atividades de lazer.

O conjunto de dados levantados na pesquisa revela aspectos importantes sobre a realidade dos pós-graduandos, como a falta de tempo livre destinado ao lazer, atividade de suma importância à saúde do ser humano. Para Carvalho e Cunha (2006) o lazer é um dos aspectos estruturantes da saúde mental, atividade de intervenção no processo saúde-doença do ser humano. Nesse contexto parece importante a implantação de programas de lazer dentro das universidades e organizações, visto que a maior parte do tempo da amostra de pós-graduandos estudada é dedicada ao estudo e trabalho. 
Acreditamos que um aprofundamento de cunho qualitativo, poderia oferecer outros encaminhamentos a fim de se configurar o tempo do estudante de pós graduação e como este elege seu tempo de lazer. Esclarecendo o que o orienta a apontar sua falta de tempo para as atividades de lazer, mesmo que não se possa afirmar categoricamente que algumas atividades desenvolvidas por eles não possam envolver certo nível de lazer, como por exemplo, ler.

São notáveis as evidências, por exemplo, da correlação entre atividades de lazer e o gênero, merecendo destaque os resultados encontrados referentes à frequência das atividades de lazer desenvolvidas pelos homens. O jogo foi a única atividade realizada com maior frequência pelos homens em relação ao gênero feminino. Futuras pesquisas devem ser conduzidas para confirmar esses resultados, além de buscar outras atividades de lazer desenvolvidas pelos homens que não estão elencadas no instrumento utilizado (EHL).

Sabemos que é um desafio refletir sobre atividades de lazer no contexto onde se privilegia o trabalho e as atividades ditas produtivas, tendo em vista um sistema baseado na reprodução continua e ampliada de mecanismos que procuram de todas as formas explorarem os trabalhadores até no próprio tempo onde o trabalhador tem por direito se ausentar do seu posto. Especialmente nessa amostra que além de atender as demandas laborais os pós-graduandos necessitam responder as exigências de âmbito universitário.

Como esta pesquisa foi desenvolvida apenas com pós-graduandos de apenas uma universidade de Fortaleza-CE, cabe ainda, sugerir proposta de pesquisas comparativas entre estudantes de outras universidades da cidade. 


\section{REFERENCIAS}

CARVALHO, S. R.; CUNHA, G. T. A gestão da atenção na saúde: elementos para se pensar a mudança da organização na saúde. In: CAMPOS, G. W. S. et al. (Org.). Tratado de saúde coletiva. São Paulo: Hucitec, 2006. p. 837-868.

CENTRO DE GESTÃo E ESTUDOS ESTRATÉGICOS - CGEE. Doutores 2010: Estudos da demográfica da base técnico-científica brasileira. Brasília: Centro de Gestão e Estudos Estratégicos, 2010.

FARO. Estresse e estressores na pós-graduação: estudo com mestrando e doutorandos no Brasil. Psicologia: Teoria e Pesquisa, v. 29, n. 1, p. 51-60, 2013.

FORMIGA, N. S.; DIAS, P. S. Correlatos entre hábitos de lazer e os indicadores do rendimento escolar. $O$ portal dos Psicólogos, p. 1-11. Disponível em: $<$ http://www.psicologia.pt/artigos/textos/A0390.pdf>. 2002. Acesso em: 25 nov. 2013.

AYROZA, I.; DIAS, L. Escala das atividades de hábitos de lazer: construção e validação em jovens. Revista de Psicologia da Vetor, v. 6, n. 2, p. 71-79, 2005.

. MELO, G.; LIMA, S. F. C. Verificação empírica da escala das atividades de hábitos de lazer em jovens esportistas e não esportistas das cidades de Terezina - PI e João Pessoas - PB. Revista Licere, Belo Horizonte, v. 16, n. 1, p. 1-21, 2013.

GUTIERREZ, G.; ALMEIDA, M. B. Cultura e Lazer: uma aproximação habermasiana. Lua Nova, São Paulo, n. 74, p. 93-130, 2008.

INSTITUTO BRASILEIRO DE GEOGRAFIA E ESTATÍSTICA - IBGE. Síntese de indicadores sociais: Uma análise das condições de vida da população brasileira. Brasília: Ministério do Planejamento, Orçamento e Gestão. Disponível em: $<\mathrm{ftp}$ ://ftp.ibge.gov.br/Indicadores_Sociais/Sintese_de_Indicadores_Sociais_2012/SIS_2 012.pdf>. 2012. Acesso em: 28 nov. 2013.

MARTONI, F. R.; SCHWARTZ, G. M. O lazer na vida do estudante universitário. Revista Digital, v. 11, n. 97, 2006. Buenos Aires. Disponível em: $<$ http://www.efdeportes.com/efd97/lazer.htm>. Acesso em: 15 nov. 2013.

NASSIF, L. O ranking das cidades mais violentas do mundo. Jornal GGN. Disponível em: $<$ http://jornalggn.com.br/noticia/o-ranking-das-cidades-mais-violentas-do-mundo $>$. 2014. Acesso em: 29 abr. 2014.

OLIVEIRA, M. B.; et al.. A gente quer comida, diversão e arte: o lazer dos estudantes universitários. Revista Brasileira de Economia Doméstica, v. 24, n. 1, p. 178-206, 2013.

PAIM, M. C.; et al. Atividades de lazer praticadas por acadêmicos da UFSM no seu tempo livre. Revista Digital, v. 10, n. 69, 2004. 
PRATTA, E. M. M; SANTOS, M. A. Lazer e uso de substâncias psicoativas na adolescência: possíveis relações. Psic.: Teor. e Pesq., Brasília, v. 23, n. 1, p. 43-52, 2007.

QUEIROZ, M. N. G.; SOUZA, L. K. Atividade de Lazer em Jovens e Adultos: um estudo descritivo. Revista Licere, Belo Horizonte, v. 12, n. 3, p. 1-21, 2009.

RODRIGUES, C.; STEVAUX, R. P. Do chronos ao kairos: os tempos da educação para o lazer. Lazer e Sociedade, v.1, p. 28-42, 2010.

SALIS, V. Ócio: da Antiguidade ao século XXI. In: CABEZA, M.C.; MARTINS, J. C. Ócio para viver no século XXI. Fortaleza: As Musas, 2008.

SCHWARTZ, G. M. O conteúdo virtual do lazer: contemporizando Dumazedier. Revista Licere, Belo Horizonte, v. 6, n. 2, p. 23-31, 2003.

SENNET, R. A Corrosão do Caráter: Consequências Pessoais do Trabalho no Novo Capitalismo. Rio de Janeiro: Record, 2010.

SILVA, R. A. Lazer e processos educativos: o olhar de gestores de clubes de empresa. 2008. 65 f. Monografia (Pós-Graduação Lato Sensu em Lazer) - Escola de Educação Física, Fisioterapia e Terapia Ocupacional, Universidade Federal de Minas Gerais, Belo Horizonte, 2008.

- Valores Humanos e Hábitos de Lazer: um estudo correlacional em jovens. Psicologia Argumento, v. 27, n. 56, p. 23-33, 2009.

VERHINE, R. E. Pós-graduação no Brasil e nos Estados Unidos: Uma análise comparativa. Educação, Porto Alegre, v. 31, n. 2, p. 166-172, 2008.

ZONTA, R.; ROBLES, A. C. C.; GROSSEMAN, S. Estratégias de enfrentamento do estresse desenvolvidas por estudantes de Medicina da Universidade Federal de Santa Catarina. Revista Brasileira de Educação Médica, v. 30, n. 3, p. 147-153, 2006.

\section{Endereço dos Autores:}

Silvia Fernandes do Vale

Rua: São Gabriel, 250, ap. 201 - Bairro: Cocó

Fortaleza - CE - 60.135-450

Endereço Eletrônico: sfvale@hotmail.com

José Clerton de Oliveira Martins

Av. Santos Dumont, 6915, apto. 502

Fortaleza - CE - 60190-800

Endereço eletrônico: jclerton@terra.com.br 